\title{
Retinopathy of Valsalva Post Oesophageal-Gastroduodenal Fibroscopy: Case Report and Review of the Literature
}

\author{
El marzouqi B*, Karmoun S, Amhoud K, Bouzoubaa T, Pr Abdelah E, Pr Boulanouar A, Pr Berraho A.
}

Department of Ophtalmology B, Ibn Sina Hospital University, hospital of specialty Rabat Morocco

DOI: $10.36347 /$ sjmcr.2020.v08i02.043

| Received: 13.02.2020 | Accepted: 20.02.2020 | Published: 29.02 .2020

*Corresponding author: El marzouqi Batal

Abstract

Introduction: Valsalva retinopathy is a rupture of vessels retinas during a physical exertion performed at closed glottis. It is linked to a sudden increase in intra-thoracic or intra-abdominal pressure. Materials and Methods: This is an elderly patient 27 years old, with no pathological history, who consult for a sudden visual acuity decrease in both eyes post oesogastroduodenal fibroscopy. The fundus revealed hemorrhages retinniene and pre - macular of both eyes. Fluorescein angiography showed no abnormality of retinal vessels. Macular OCT is normal. Discussion: Valsalva retinopathy usually occurs in healthy adults it has been reported after aerobic exercise, vigorous sexual activity, swelling balloons, prostate, dental surgery, episodes of constipation, vomiting and uprisings in pregnant women. After weightlifting, endotracheal intubation, vomiting, coughing with force, colonoscopy procedure, and in rare cases after upper gastrointestinal endoscopy. Valsalva-induced preretinal hemorrhage generally present in the macula. In case of macular damage, Valsalva retinopathy may cause a sudden decrease in vision. As a general rule, the visual prognosis is favorable usually, it is impossible to clinically distinguish the plan from premacular hemorrhage, sub-hyaloid ... From where the interest of fluoride angiography and macular OCT. In case of sudden loss of vision during a diagnostic procedure, the doctor may time and effort to try to determine the cause. If Valsalva maneuver is noted in the story, however, valsalva retinopathy should be considered as a possible explanation for vision loss. The evolution of retinopathy of Valsalva is most often spontaneously favorable. $\mathrm{Nd}$ - yag laser or vitrectomy are only performed in case of persistence of the hematoma because of risk of retinal toxicity. Conclusion: Retinopathy of valsalva is a rare condition with a good prognosis; its diagnosis is based on the clinical history. It does not require recourse physical or surgical treatment except in the event of a functional threat.

Keywords: Retinopathy, valsalva, haemorrhage, oesophageal-gastroduodenal fibroscopy, reduced visual acuity, reduced visual acuity.

Copyright @ 2020: This is an open-access article distributed under the terms of the Creative Commons Attribution license which permits unrestricted use, distribution, and reproduction in any medium for non-commercial use (NonCommercial, or CC-BY-NC) provided the original author and source are credited.

\section{INTRODUCTION}

Valsalva retinopathy is a rupture of vessels retinas during a physical exertion performed at closed glottis. It is linked to a sudden increase in intra-thoracic or intra-abdominal pressure [1]; any expiratory maneuver with a closed glottis is called a Valsalva maneuver. It leads to an increase in intrathoracic and abdominal pressure and therefore a reduction in venous return. Immediately after a Valsalva maneuver, there is a sudden increase in intraocular venous pressure potentially responsible for spontaneous rupture of the retinal capillaries, leading to the formation of a hematoma under the internal limiting membrane (MLI) and sometimes retrohyaloid. This pathological manifestation is called Valsalva retinopathy (RV) and was first described in 1972 by Thomas Duane

\section{OBSERVATION}

It is a $\mathrm{HB}$ patient aged 28 years, history of cesarean delivery in 2016, having as profession professor of higher education, followed in gastrology for chronic gastritis, who presented in post-fibroscopy esogastroduodenal, perform under general anesthesia, a sudden drop in visual acuity, in which the clinical examination revealed a visual acuity without correction $8 / 10$ weak and a visual acuity at $9 / 10$ with correction (right eye: -0.5 at $85^{\circ}$ and the left eye -0.75 to $75^{\circ}$ ). Examination with a slit anterior segment lamp without any particularities and the fundus of the peri-vascular and peri-macular hemorrhages in both eyes (Figure 1) 


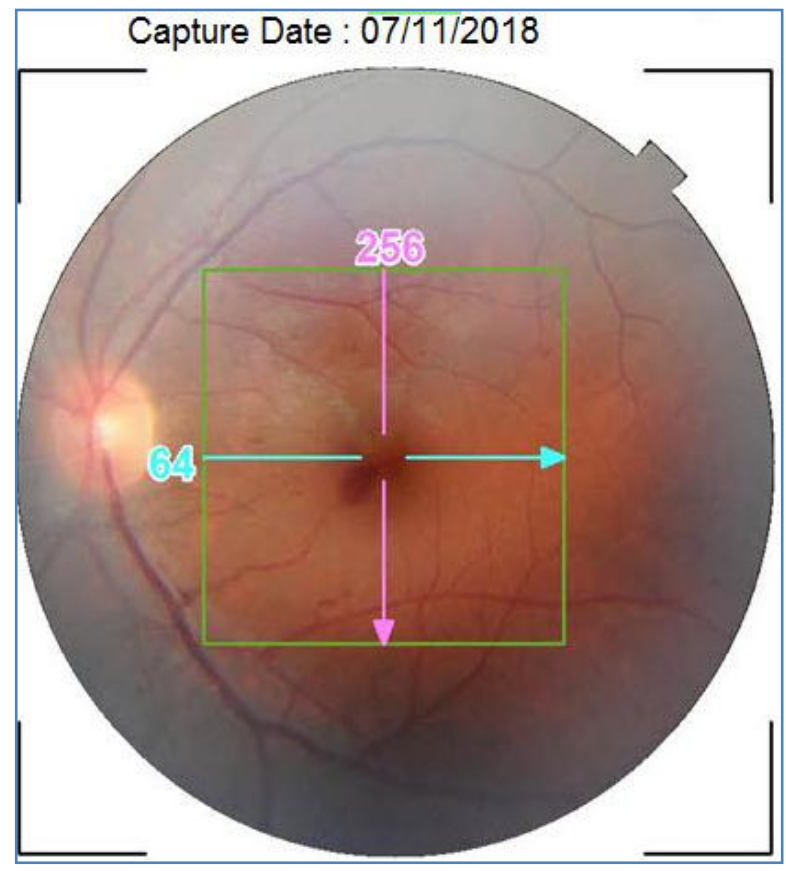

Fig-1: Color photo of the fundus (left eye) with a perimaular hemorrhage and multiple small perivascular hemorrhages

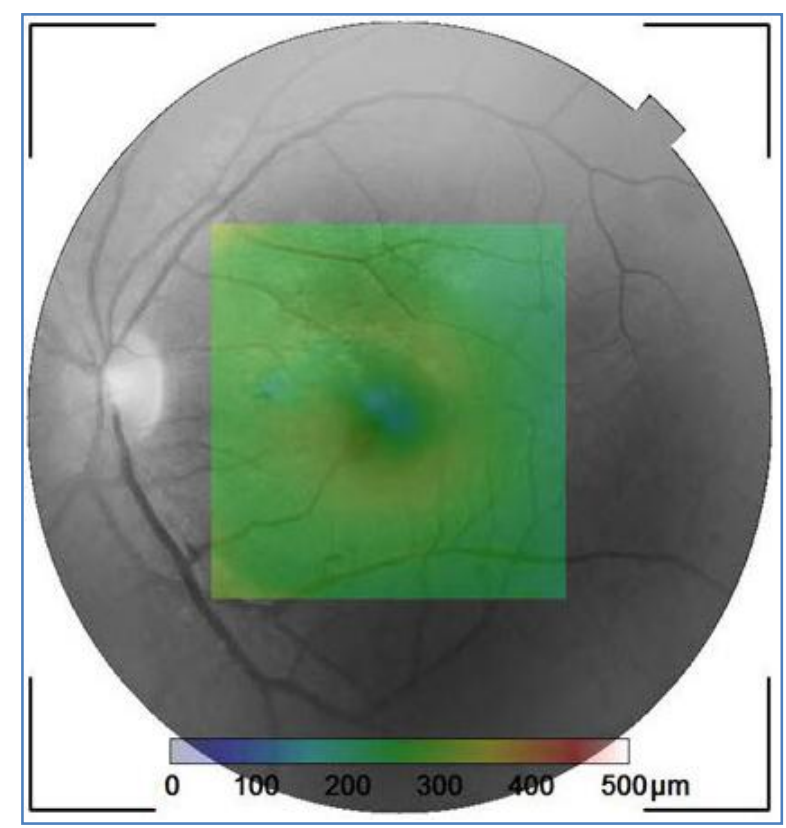

Fig-2: Photo with green filter of the same eye

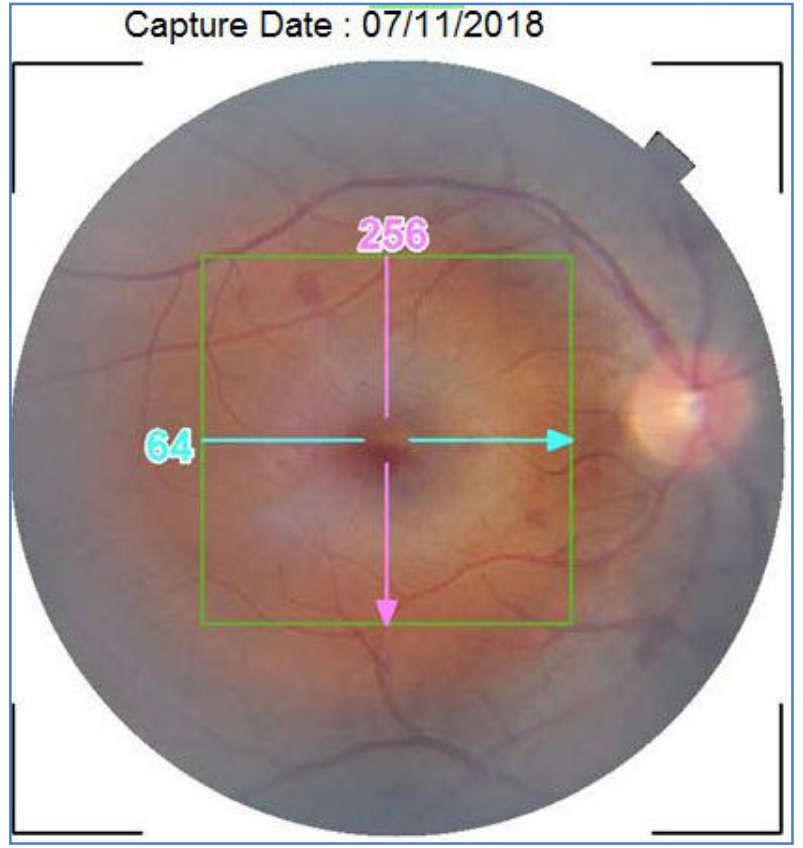

Fig-3: Color photo of the fundus (right eye) with multiple perivascular hemorrhages

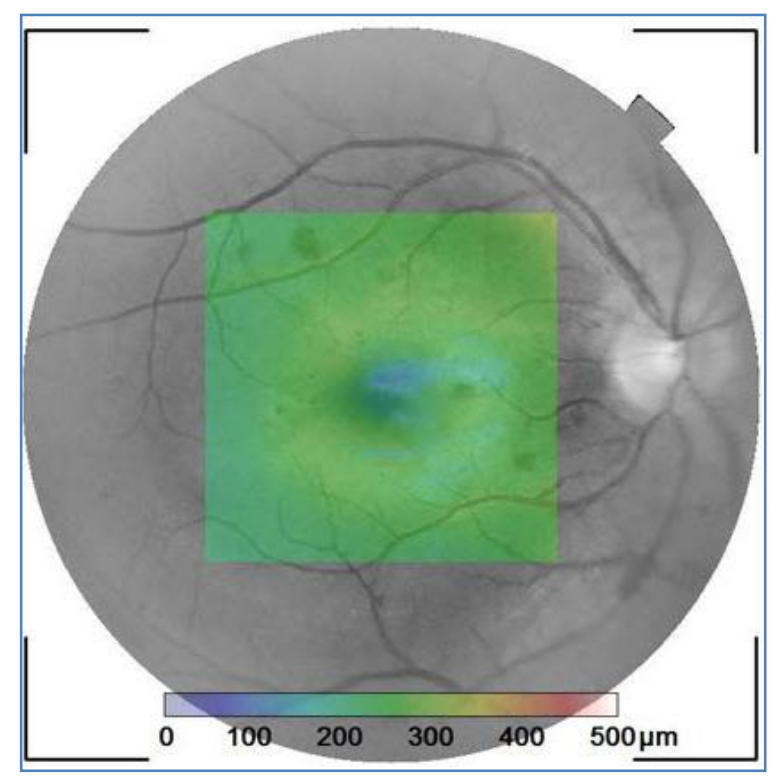

Fig-4: Photo with green filter of the same eye

A macular optical coherence tomography (OCT) of the two eyes was performed, which did not objectify a macular hematoma (figure 5,6 ) 


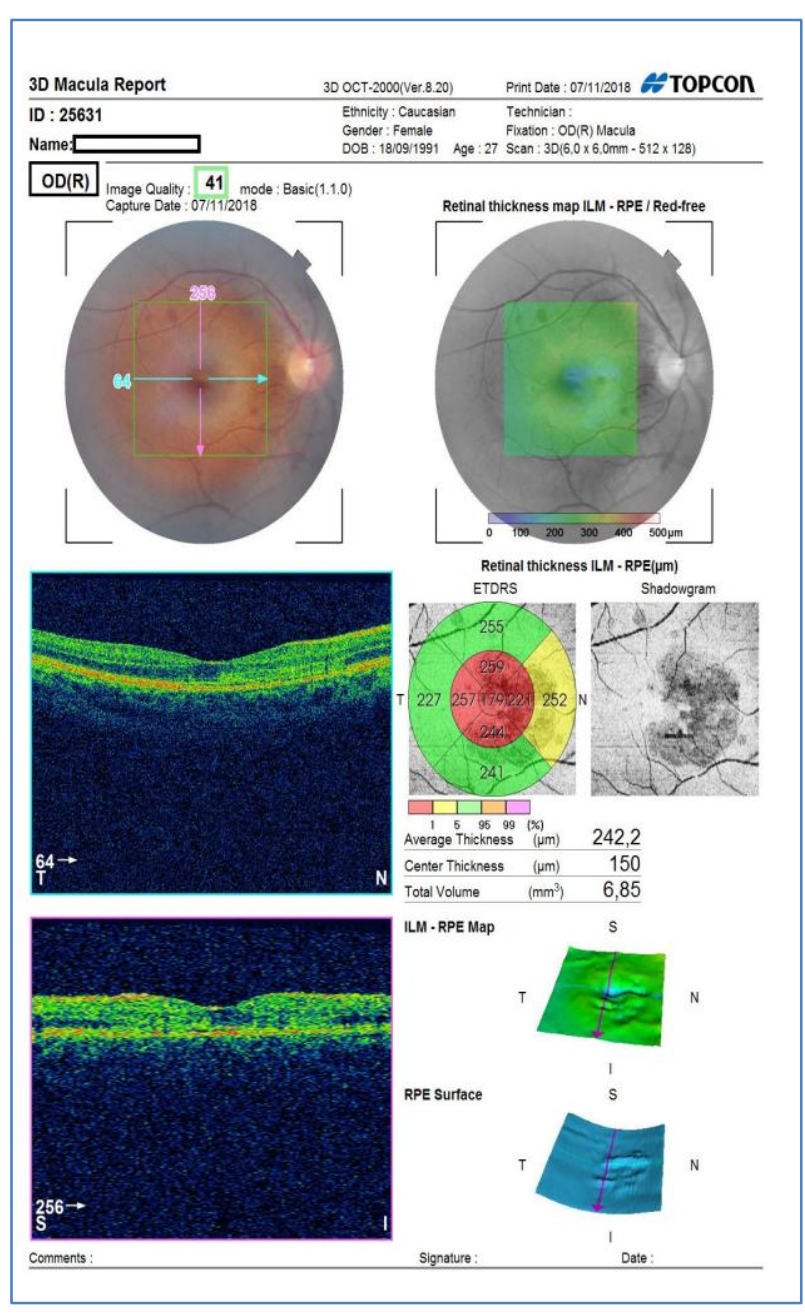

Fig-5: Macular OCT of the right eye: absence of hemorrhage or macular hematoma

After one month, the evolution was marked by the disappearance of the visual blur with visual acuity without correction of $10 / 10$ at the level of the two eyes, the fundus, and a disappearance of the retinal hemorrhages (Figure 6).

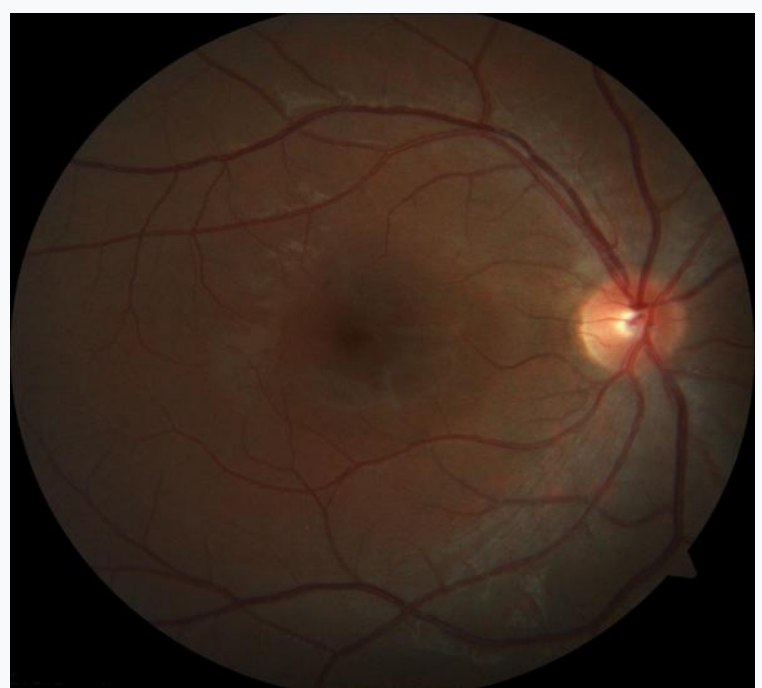

Fig-6: Color photo of the fundus (right eye) after a month of evolution

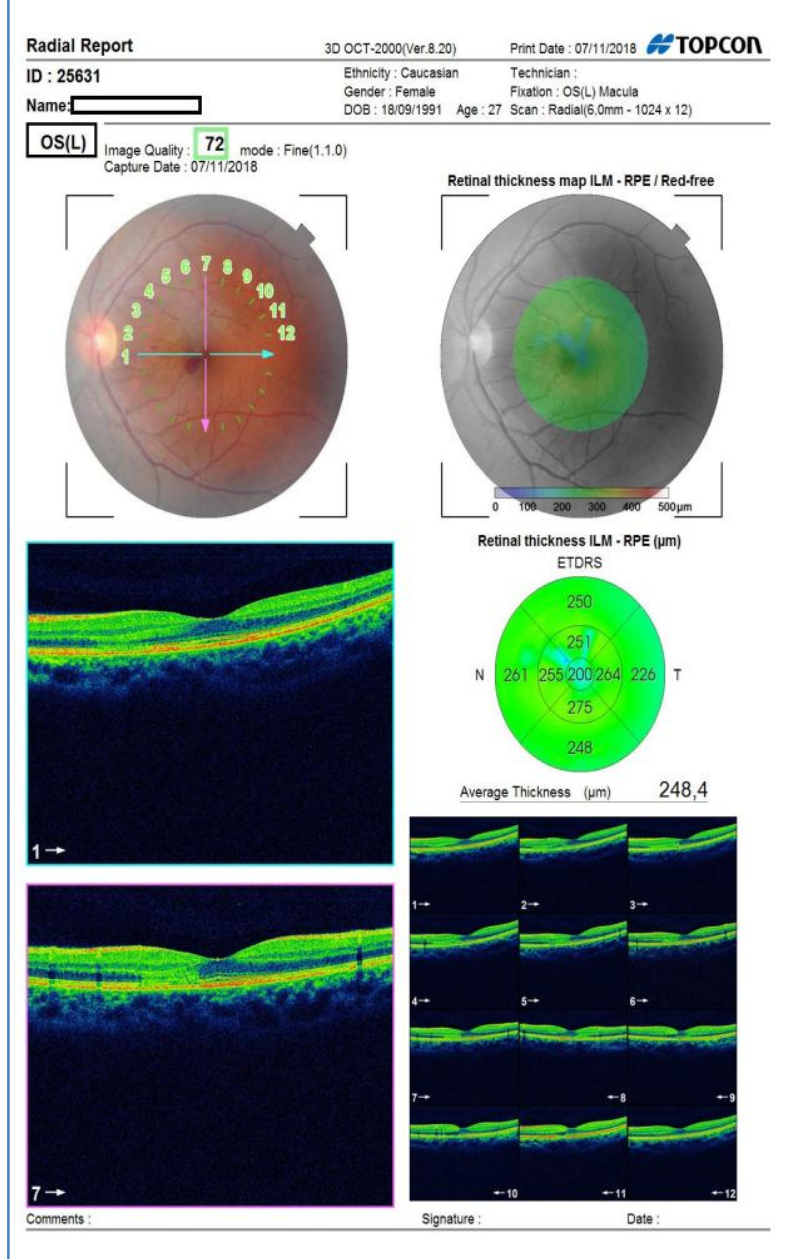

Fig-5: Macular OCT of the left eye: absence of hemorrhage or macular hematoma

\section{DISCUSSION}

Valsalva Retinopathy is a rare disease but affects young active subjects who generally do not have any underlying ophthalmological or systemic pathology. Initial therapeutic abstention and observation are classically recommended for three weeks after the initial diagnosis [3]. It has been reported after aerobic exercise, vigorous sexual activity, swelling balloons, and prostate, dental surgery, episodes of constipation, vomiting and uprisings in pregnant women. After weightlifting, endotracheal intubation, vomiting, coughing with force, colonoscopy procedure, and in rare cases after upper gastrointestinal endoscopy. Valsalva-induced preretinal hemorrhage generally present in the macula. In case of macular damage, Valsalva retinopathy may cause a sudden decrease in vision. As a general rule, the visual prognosis is favorable usually, it is impossible to clinically distinguish the plan from premacular hemorrhage, subhyaloid [4, 5]. From where the interest of fluoride angiography and macular OCT. In case of sudden loss of vision during a diagnostic procedure, the doctor may time and effort to try to determine the cause. If Valsalva maneuver is noted in the story, however, valsalva retinopathy should be considered as a possible 
explanation for vision loss. The evolution of retinopathy of Valsalva is most often spontaneously favorable. $\mathrm{Nd}$ yag laser or vitrectomy are only performed in case of persistence of the hematoma because of risk of retinal toxicity $[6,7]$.

\section{Conclusion}

Retinopathy of valsalva is a rare condition with a good prognosis; its diagnosis is based on the clinical history. It does not require recourse physical or surgical treatment except in the event of a functional threat. The $\mathrm{Nd}$ - yag laser or vitrectomy are only performed if the hematoma persists because of the risk of retinal toxicity [1].

\section{REFERENCES}

1. Mana, S., Belarbi, S., Bouziani, O., Benhamada, Z., Ailem, A., \& Hartani, D. (2008). 474 La rétinopathie de Valsalva: à propos de deux cas. Journal Français d'Ophtalmologie, 31, 153.
2. Duane T.D.

Valsalva hemorrhagic retinopathy Trans Am Ophthalmol Soc. 1972; 70 : 298-313

3. Durukan AH, Kerimoglu H, Erdurman C, Demirel A, Karagul S. Long-term results of Nd:YAG laser treatment for premacular subhyaloid haemorrhage owing to Valsalva retinopathy Eye (Lond). 2008; 22: 214-218

4. Choi S, Lee S, Rah S. Valsalva retinopathy associated with fiber optic gastro enteroscopy. Can J Ophthalmol.2006;41(4):491-3.

5. Kim J, Lee D, Lee J. Valsalva retinopathy associated with an oratorical contest. Ko J Ophthalmol. 2009;23:318-20.

6. Ladjimi A, Zaouali S, Messaoud R, Ben Yahia S, Attia S, Jenzri S, Khairallah M. Valsalva retinopathy indiced by laber. 2002;12(4):336-8.

7. Patane PS, Krummenacher TK, RAO RC. Valsalva hemorrhagic retinopathy presenting as a rare cause of impaired vision after a general anesthetic _ a case report and review of the literature. J Clinic Anesth. 2015;27: 341-6. 